\title{
Get Your Feet Wet! - Experiential Learning Activities along Lost Creek
}

Dr. Jennifer Mueller Price, Rose-Hulman Institute of Technology

Dr. Sue Niezgoda P.E., Gonzaga University 


\title{
Get Your Feet Wet! - Experiential Learning Activities along Lost Creek
}

\begin{abstract}
Since 2008, Lost Creek, a stream that runs through the Rose-Hulman Institute of Technology (RHIT) campus, has been utilized as an outdoor lab in Civil Engineering classes. Experiential learning activities have primarily been applied to a stream restoration course as part of a baseline monitoring program for the planned restoration of Lost Creek. The course is structured around conducting weekly field labs along Lost Creek. In this environmental river mechanics / stream restoration course, students are introduced through field labs to the concepts of fluvial geomorphology, aquatic ecosystems, and sediment transport for application in restoring impaired streams. During the quarter, the students make frequent visits to Lost Creek for the purpose of collection baseline monitoring data that is used to classify channel morphology and process, analyze stream habitat characteristics, estimate sediment transport, and analyze stream stability. The data collected during this course contributes to student learning, but also contributes to a growing database of pre-restoration monitoring of baseline conditions. By integrating experiential learning activities along Lost Creek into established civil engineering courses, we strive to enhance student knowledge of open channel hydraulics and environmental river mechanics. The effects of experiential learning activities on student learning of natural stream processes and stream restoration were measured through an analysis of the Index of Learning Styles and a qualitative assessment of student comments on course evaluations. Educational outcomes of experiential learning have been quite positive based on student feedback. The students commented that they gained a lot of valuable experience when conducting field surveys of stream geometry and sediment characteristics. During summer 2014, a restoration design will be implemented along Lost Creek, and future courses will continue to monitor the effectiveness of the restoration project with respect to stream stability. An analysis of the Index of Learning Styles and student evaluation comments will continue to be examined to determine the impact experiential learning activities have on the student learning. This has been and will continue to be a unique opportunity for students to be involved in a pre- and post-restoration monitoring program of a real world project.
\end{abstract}

\section{Introduction to Experiential Learning Activities}

As defined by the Association for Experiential Education, "Experiential education is a philosophy that informs many methodologies in which educators purposefully engage with learners in direct experience and focused reflection in order to increase knowledge, develop skills, clarify values, and develop people's capacity to contribute to their communities."1 The Experiential Learning Theory (ELT) highlights "experience” as a key role in the learning process. $^{2}$ The ELT process is an integrated cycle of gaining knowledge through a Concrete Experience (CE), upon which is the basis for Reflective Observation (RO), followed by gathering these reflections through Abstract Conceptualization (AC) to develop inferences and generate new experiences of Active Experimentation (AE). ${ }^{2}$

Teaching a course in environmental river mechanics / stream restoration provides an opportunity to incorporate experiential learning, as the direct experience of working in the field to collect and 
analyze data is essential to a deeper understanding of stream processes. Throughout the course, we participate with the students in weekly field experiences of collecting measurements and visual observations along Lost Creek, coupled with report submittals that analyze and reflect upon the work completed. Although the RHIT Civil Engineering department incorporates hands-on, laboratory activities in other courses, including Hydraulic Engineering, Environmental Engineering, and Civil Engineering Materials, these are primarily conducted in an indoor, scaled laboratory setting. Because students in CE598-01 utilize Lost Creek, a full-scale stream, as their outdoor lab, they have the opportunity to work directly with a real, natural system, as opposed to a simulated or bench-scale system. This direct learning opportunity requires them to interpret and analyze processes in a real stream instead of a hypothetical situation or case.

Prior work on experiential learning in higher education stresses the need to connect student learning styles with the learning environment. ${ }^{3}$ Additionally, experiential learning activities create more interaction between students and their instructors outside of the traditional classroom setting, which can help with anxiety among students and help instructors become more involved with students' reactions to these learning experiences. ${ }^{4}$ This is the type of learning environment we've worked to create in CE598-01.

\section{Course Overview}

CE598-01 Stream Restoration / Environmental River Mechanics is a senior technical elective course taught in the Civil Engineering Department during Spring Quarter. The course typically covers topics of fluvial geomorphology, fluvial hydraulics, sediment transport, and ecological processes in alluvial rivers for application in solving common design problems and restoring impaired streams. The course is composed of three 50-minute class meetings and a three-hour laboratory each week. During Spring 2013, the following learning objectives were developed for the course:

1. Classify stream types based on channel evolution stages, stream order, and other common classification methods

2. Describe various channel forming flows and identify bankfull using field indicators, regional hydraulic geometry curves, and rating curves

3. Apply Lane's Balance to evaluate channel response to change

4. Utilize hydraulic geometry relationships to investigate channel stability

5. Examine how ecological processes are interconnected in a river system and describe trends associated with the river continuum concept

6. Demonstrate how alterations to the natural flow regime affect ecological processes

7. Calculate insipient motion of sediment particles based on Shields' dimensionless shear stress

8. Examine sediment transport by utilizing principles of stream power and applied shear stress, and conduct sediment supply-capacity analyses

9. Perform field data collection of channel geometry, bed and bank material characterization, and water quality parameters

10. Develop a stable channel design based on stream processes and channel form

A key component of this course is the development of a deeper understanding of stream processes by incorporating field labs that act as experiential learning experiences. These field 
labs tie in nicely with the overall course objectives and generate a very positive response from students in the course, as they all embrace the opportunity to truly get their feet wet in the course material.

\section{Integration of Experiential Learning Activities}

Experiential learning activities for CE598-01 were developed as part of a baseline monitoring plan for the restoration of Lost Creek. The monitoring plan was finalized for the Lost Creek Field Lab based on the following four primary objectives:

1. Provide initial physical data for stream analysis and restoration design

2. Provide baseline monitoring data for use in post-construction effectiveness evaluations

3. Integrate undergraduate lab work and work study opportunities into monitoring data collection

4. Identify changes in existing design parameters prior to project construction

The plan was developed using a list of the physical attributes adapted from the National Engineering Handbook Part 654: Stream Restoration Design ${ }^{3}$. Each attribute provides various parameters for evaluation, and each parameter requires various data to be collected in the field. As such, we have developed a set of laboratory experiences (i.e., experiential learning activities) that are used to collect and analyze this attribute data as well as reinforce classroom concepts and problems. In addition to the concrete field experience itself, students are also required to reflect upon their experience by discussing visual observations, analyzing and interpreting data collected, and drawing conclusions based on their experience and reflections. This procedure is meant to emulate the ELT process. Examples of the baseline monitoring plan field laboratory experiences include the following:

- Survey cross-sectional and longitudinal profiles

- Measure velocity and calculate discharge

- Estimate channel roughness

- Size channel bed material

- Describe bank material characteristics

- Classify stream types

- Evaluate stream stability and bank erodibility based on established protocols

- Apply visual stream protocol to assess stream condition

- Characterize instream habitats

- Conduct water quality measurements

Examples of analyses and reflections to probe abstract conceptualization and experimentation include the following:

- Explain why there may be differences in discharge measurements

- Discuss whether you think Lost Creek is a stable stream reach and explain why

- Describe what bank erodibility measures mean with respect to channel stability and the potential impacts on surrounding property 
- Discuss any additional indicators missing from the protocols that might be important in assessing stability at this site

- Describe implications for continued stability in response to direct changes to the stream or land use changes upstream

- Assess how habitat types and particular water quality parameters affect aquatic life

The experiential learning activities (i.e., field laboratory exercises) were created to guide students in the data collection efforts. Although the activities are most often applied in CE59801, each activity is transferrable and was not designed for any specific course, but instead can function as an independent monitoring procedure or be utilized in other courses. The field work for each lab was designed to be completed in a two to four hour period and was also made easily accessible for work study and volunteer student monitors. Table 1 identifies the experiential learning activities created, the data collected, and other courses or entities that can utilize the experiential learning activities for data collection. Figure 1 provides an example of one experiential learning activity created and currently in use by students in CE598-01. Figures 2 and 3 show undergraduate students getting their feet wet and applying the activities to collect data in Lost Creek as part of CE598-01.

Table 1: Data Collection in Experiential Learning Activities of Lost Creek

\begin{tabular}{|c|c|c|}
\hline $\begin{array}{l}\text { Experiential Learning } \\
\text { Activity }\end{array}$ & Data Collected & Collection Entity \\
\hline \multirow[b]{2}{*}{ Stream Survey Lab } & Cross-section Profile & \multirow{2}{*}{$\begin{array}{l}\text { CE598-01 Stream Restoration, } \\
\text { CE567 Applied Hydrologic } \\
\text { Modeling, Work } \\
\text { Study/Summer Research } \\
\text { Students }\end{array}$} \\
\hline & Longitudinal Profile & \\
\hline \multirow{3}{*}{$\begin{array}{l}\text { Bed/Bank Material } \\
\text { Characterization }\end{array}$} & Wolman Pebble Counts & \multirow{3}{*}{ CE598-01 Stream Restoration } \\
\hline & $\begin{array}{l}\text { Volumetric Sediment } \\
\text { Samples }\end{array}$ & \\
\hline & Particle Size Distributions & \\
\hline Bank Erodibility & BEHI Characteristics* & CE598-01 Stream Restoration \\
\hline \multirow[b]{2}{*}{ Discharge Measurements } & Stream Flow & \multirow{2}{*}{$\begin{array}{l}\text { CE598-01 Stream Restoration, } \\
\text { CE567 Applied Hydrologic } \\
\text { Modeling, Work } \\
\text { Study/Summer Research } \\
\text { Students }\end{array}$} \\
\hline & $\begin{array}{l}\text { Manning's Roughness } \\
\text { Coefficient }\end{array}$ & \\
\hline \multirow{4}{*}{$\begin{array}{l}\text { Ecology and Habitat } \\
\text { Analysis }\end{array}$} & Macroinvertbrate Counts & \multirow{4}{*}{$\begin{array}{l}\text { ABBE320 Ecology, } \\
\text { CE598-01 Stream Restoration }\end{array}$} \\
\hline & Habitat Characteristics & \\
\hline & Water Quality Data & \\
\hline & $\begin{array}{l}\text { Riparian Vegetation } \\
\text { Transects }\end{array}$ & \\
\hline
\end{tabular}


STREAM BED AND BANK CHARACTERISTICS

This lab requires teams of two to three students. For this lab you will be collecting and analyzing samples of bed and bank materials from Lost Creek.

\section{EQUIPMENT LIST}

Each team will need the follow equipment:

- Three (3) large plastic sample bags

- Shovel

- Bank Material Characteristics Data Log Sheet

- Bank Material Classification Reference Sheet

- Pencil \& Permanent Marker

- Camera

\section{FIELD DATA COLLECTION}

1. Locate the permanent rebar markers (on both banks) for your assigned cross-section. Be sure to note your cross-section number on you Data Log sheet. You will need this information for your report.

2. Starting on the left bank (when facing downstream), take a "grab" sample from the bank. This should be a sample size that fits easily in the palm of your hand. If the surface of the bank is covered with roots or plants, dig below these using your hand or a small trowel until you can grasp a fairly clean sample.

3. Compare the appearance and texture of the sample to the "Bank Material Classification Reference Sheet". A bolus, a referred to on the reference sheet, is a "worm-shaped" mass created by moistening the sample and rolling in the palm of your hand.

4. Record the classification of the bank material.

5. Repeat this process for each apparent soil layer on the bank and for each layer on the right bank. Soil layers can be identified by changes in color, texture, or general appearance of the soil.

6. Along the cross-section, collect 5 bag samples of bed material. For each sample, stand upstream of where the sample is to be taken. This way your body will help to direct flow around the sample location. Space the sample locations evenly along the cross-section. Label each sample bag with the cross-section number in permanent marker.

7. Be sure to bring all equipment back with you. Clean and dry all equipment thoroughly before leaving the lab.

\section{LABORATORY ANALYSIS}

1. Immediately after collecting the bag samples, place the samples in separate metal pans and place in the oven until dry (at least 24 hours). Be sure to label the samples.

2. After the samples are dry, measure and record each samples mass.

3. Perform a sieve analysis on each sample. Use the $1 / 2$ ", No. 4, 8, 16, 30, 50, 100, and 200 sieves.

4. Measure and record the mass of material in each sieve and the bottom pan.

\section{DESKTOP ANALYSIS}

Your instructor will provide you with an Excel file containing past material measurements for your cross-section. Input the results from the lab analysis into this spreadsheet. Has the particle size distribution change from previous years? Why or why not? Compare you bank material classifications to those from previous years. Are they similar?

\section{REPORT}

Prepare a report containing the following:

- Plot of your bank material particle size distribution

- Comparison plot of your data with past data

- Discussion of you observations of the plot and bank material classification

- Conclusions

Figure 1: Bed and Bank Characterization Experiential Learning Activity 


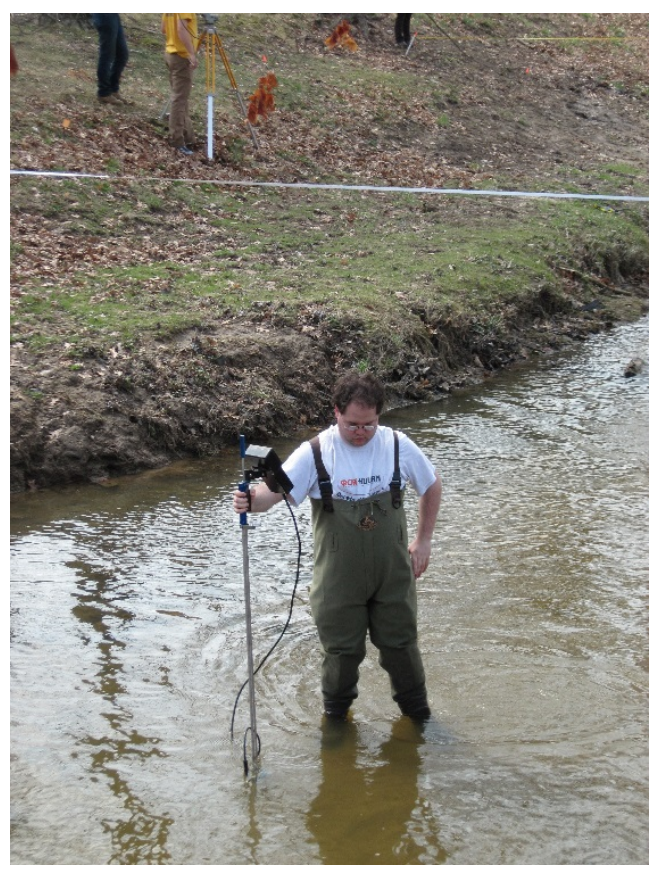

Figure 2: Senior student using the Acoustic Doppler Velocimeter to Measure Stream Flow in Lost Creek

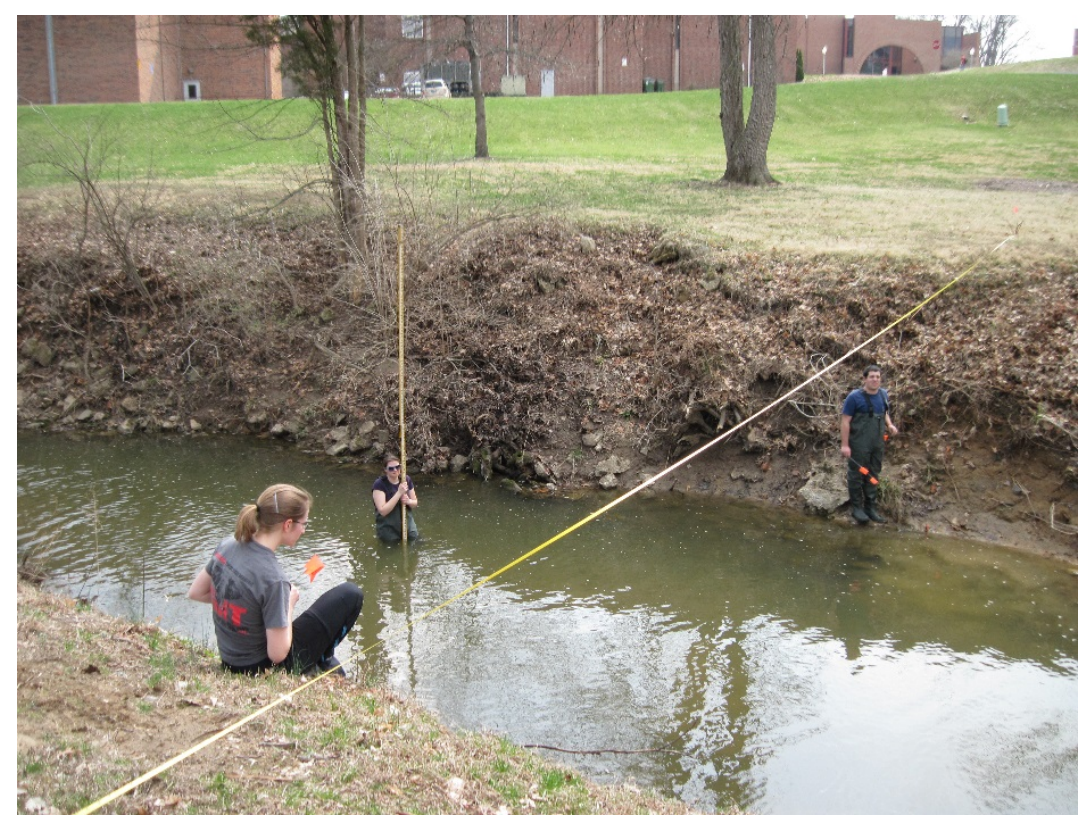

Figure 3: Junior and Senior Students Completing a Cross Section Survey of Lost Creek 


\section{Index of Learning Styles}

In support of including experiential learning in courses, we investigated the Index of Learning Styles (ILS) for the CE598-01 course in Spring 2011, 2012, and 2013. The ILS is an instrument used to assess preferences on four dimensions (active/reflective, sensing/intuitive, visual/verbal, and sequential/global) of a learning style model formulated by Felder and Silverman ${ }^{5}$. The ILS instrument was developed by Felder and Soloman ${ }^{6}$. In summary, active learners understand best by doing and applying, while reflective learners think it over first ${ }^{5}$. Sensing learners prefer doing hands-on work, while intuitive learners may better understand abstract concepts ${ }^{6}$. Visual learners understand through pictures and demonstrations, while verbal learners through written and spoken words ${ }^{6}$. Sequential learners use stepwise paths to solve problems, while global learners may tend to absorb the big picture first ${ }^{6}$.

According to these descriptions of the dimensions of learning styles, experiential learning in class would fit well with active, sensing, and visual learners. According to the ILS for students enrolled in CE598-01 during Spring 2011, 2012, and 2013, over half of the students fall into the active, sensing, and visual portions of each dimension, as shown in Table 2. Although most students in the course have been active and sensing learners, the homework assignments, written lab reports, and journal article critiques that are assigned throughout the quarter help to connect better with the reflective and intuitive learners in the class. All RHIT students complete the ILS survey at the beginning their freshman year. Figure 4 shows an example of the ILS output for students enrolled in CE598-01 during Spring 2013, provided by RHIT's Institutional Research Planning and Assessment group.

Table 2: Index of Learning Style Results for Students Enrolled in CE598-01

\begin{tabular}{|c|c|c|c|}
\hline & Active/Reflective & Sensing/Intuitive & Visual/Verbal \\
\hline CE598-01;Spring & $81 \%$ in active & $63 \%$ in sensing & $100 \%$ in visual \\
2011 & portion & portion & portion \\
\hline CE598-01;Spring & $66 \%$ in active & $77 \%$ in sensing & $100 \%$ in visual \\
2012 & portion & portion & portion \\
\hline CE598-01;Spring & $81 \%$ in active & $72 \%$ in sensing & $100 \%$ in visual \\
2013 & portion & portion & portion \\
\hline
\end{tabular}


Course: CE598-01

Response Rate: 11 of $11(100 \%)$

Title: Stream Restoration Class Profile: SR (11)

Term: Spring Quarter - 2012-13 Major Profile: CE (11)

ACTIVE

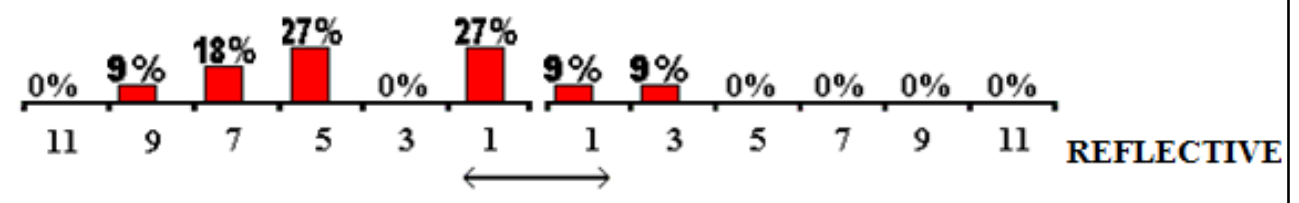

SENSING

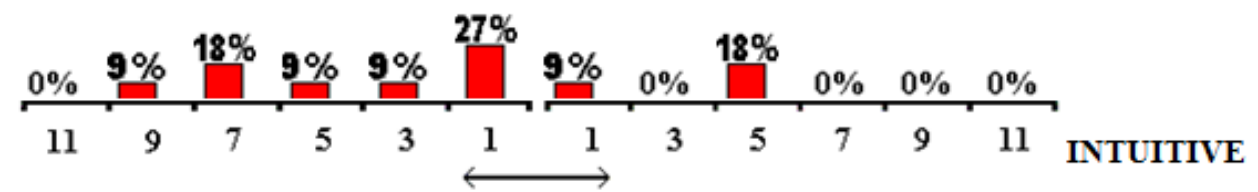

VISUAL
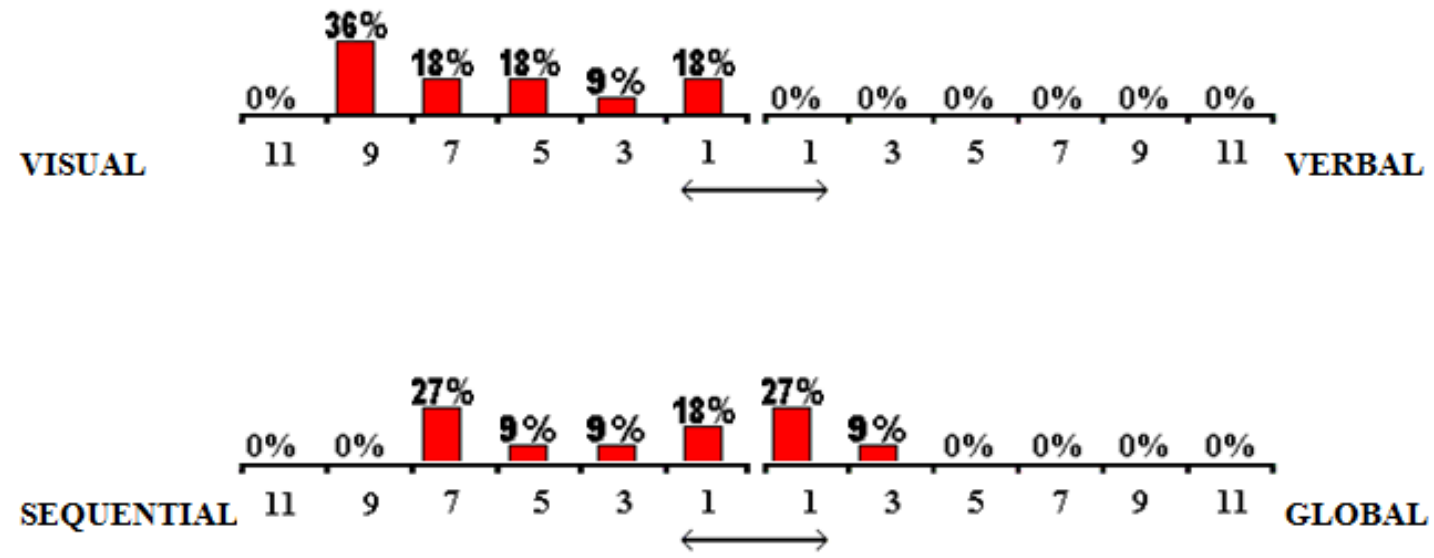

Figure 4: Index of Learning Styles for CE598-01 Students in Spring 2013

\section{Student Assessment of Learning}

The course was initially taught as a 2-credit (half-time) course in Spring 2008 and 2009. It was expanded to a full 4-credit course in Spring 2011, 2012, 2013, and 2014. For a Spring Quarter Senior Elective course, enrollment remains relatively high in the course. Data from course evaluations from Spring 2011, 2012, and 2013 exhibit an overall average course rating of 4.36/5.00 compared to an RHIT institute average of 3.88/5.00. Additionally, when commenting on the course evaluation statement that the laboratory assignments and course material reinforced one another, the overall average rating for CE598-01 is 4.77/5.00, compared to an RHIT institute average of 4.21/5.00 (with 5 being "strongly agree" and 1 being "strongly disagree"). With the 
course and laboratory activity ratings being above institute averages, these ratings show the positive effect that the experiential activities have on student learning. It can be argued that the course and student learning would not be as effective without this experiential learning component. Positive student comments reflect on the meaningful lab experiences and coincide with the learning styles of the majority of the students in the course being active, sensing, and visual learners.

Anonymous student feedback on course evaluations from Spring 2008-2013 list the following as strengths of the course.

- "Working at Lost Creek; it is near to the civil building and gives a good example of how it would be in real life."

- "We got to apply what we'd learned in class in Lost Creek. Lost Creek proved to be a very powerful learning tool, allowing us to reinforce lecture without having to go far from campus. The labs were a good way to apply some of the models and techniques into a real world situation."

- "Hands-on experience out in the field was very valuable to reinforce concepts from the classroom.”

- "Active learning and excellent lab work to go with the in-class concepts."

- "The practical, hands-on experience was beneficial."

- "I really liked the hands-on experience, and the fact that we actually used data from real streams for the problems we worked, not just a set of hypothetical information. It was useful to learn where to gather the information needed to apply the methods, too, for future reference.”

- "Very useful material and the in-field labs were a lot of fun. I really liked the hands-on aspects and measurements.”

\section{Conclusions}

Through the lab experiences in this course, students have gained a more holistic understanding of natural stream processes, as well as practical field measurement skills. The ILSs for students enrolled in the course and student feedback support the use of experiential learning in this course. During summer 2014, a restoration design will be implemented along Lost Creek, and we will continue to monitor stream stability. Student evaluation comments will continue to be examined to determine the impact experiential learning activities have on the student learning. This has been and will continue to be a unique opportunity for students to be involved in a preand post-restoration monitoring program of a real world project.

\section{Bibliography}

1. Association for Experiential Education (AEE). 2013. http://www.aee.org/ (accessed December 2013).

2. Kolb, D.A., R.E. Boyatzis, C. Mainemelis. 2000. Experiential Learning Theory: Previous Research and New Directions. In R.J. Sternberg and L.F. Zhang (Eds.), Perspectives on cognitive, learning, and thinking styles. NJ: Lawrence Erlbaum. 
3. Kolb, A.Y, and D.A. Kolb. 2005. Learning Styles and Learning Spaces: Enhancing Experiential Learning in Higher Education. Academy of Management Learning and Education 4(2):193-212.

4. Hickcox, L.K. 2002. Personalizing Teaching through Experiential Learning. College Teaching 50(4): 123128.

5. United States Department of Agriculture-Natural Resources Conservation Service (USDA-NRCS). 2007. National Engineering Handbook Part 654 - Stream Restoration Design.

6. Rosgen, D. L. 2001. A Practical Method of Computing Streambank Erosion Rate. Wildland Hydrology, Inc. Pagosa Springs, CO.

7. Felder, R.M. and L.K. Silverman. 1988. Learning and Teaching Styles in Engineering Education. Engineering Education 78(7):674-681.

8. Felder, R.M. and B.A. Soloman. Learning Styles and Strategies. North Carolina State University. Index of Learning Styles Instrument. 